\title{
Globulin to Creatinine Ratio Measurement
}

National Cancer Institute

\section{Source}

National Cancer Institute. Globulin to Creatinine Ratio Measurement. NCI Thesaurus.

Code 142276

The determination of the ratio of g lobulin compared to creatinine present in a sample.

The measurement may be expressed as a ratio or percentage. 